Romeo C. Sanchez Jr., MD', Benjamin SA Campomanes Jr., MD ${ }^{1,2}$, Natividad A. Aguilar, MD, MSc ${ }^{1,3}$

'Department of OtorhinolaryngologyHead and Neck Surgery

East Avenue Medical Center

${ }^{2}$ Department of Otolaryngology Head and Neck Surgery St. Luke's Medical Center

${ }^{3}$ Department of Otolaryngology Head and Neck Surgery Manila Central University
Correspondence: Romeo C. Sanchez Jr., MD

Department of ORL-HNS

East Avenue Medical Center

East Avenue, Diliman, Quezon City 1100

Philippines

Phone: (632) 9271128

E-mail: dooderts1@yahoo.com

Reprints will not be available from the author.

Funding support: The test drug Methylprednisolone and the placebo were provided by Pfizer Inc., 23/F Ayala FGU, 6811 Ayala Ave., Makati City. Other than this, the authors signed a disclosure that they have no proprietary or financial interest with any organization that may have a direct interest in the subject matter of this manuscript, or in any product used or cited in this study.

Presented at:

1. Analytical Research Contest (3rd Place) Philippine Society of Otolaryngology Head and Neck Surgery 49th Annual Convention, Westin Philippine Plaza Hotel, Manila, December 1, 2005

2. 3rd East Avenue Medical Center Residents' Organization Research Paper Contest (3rd Place), East Avenue Medical Center, East Ave., Diliman, Quezon City, December 16, 2005.

\section{Low Dose, Short-Term Oral Methylprednisolone for Nasal Polyps: A Randomized Double-Blind Placebo-Controlled Trial}

\author{
ABSTRACT \\ Objectives: To determine the efficacy of a 7-day treatment of methylprednisolone $16 \mathrm{mg}$ in \\ reducing the size of nasal polyps and on improvement of nasal symptoms.

\section{Methods:} \\ Design: Randomized double-blind placebo-controlled trial \\ Setting: Out-patient department of the East Avenue Medical Center \\ Patients: Patients 18 years old and above with nasal polyposis determined by history \\ and endoscopic examination
}

Results: There was a significant decrease in polyp size by an average of $16 \%(P<.05)$ among 12 out of the 23 patients $(52.17 \%)$ in the steroid group versus placebo. The treatment group also exhibited an improvement in nasal symptoms of rhinorrhea, congestion and anosmia compared to the placebo.

Conclusion: Medical treatment with oral methylprednisolone given at a low dose of $16 \mathrm{mg}$ for one week resulted in reduction of the size of nasal polyps and improved the symptoms of rhinorrhea, nasal congestion and anosmia. Other associated symptoms like headache, epistaxis, sneezing, itchiness, epiphora, cough, postnasal drip, throat discomfort, facial pain, eye complaints and fever did not differ between the steroid and placebo groups.

Recommendation: One week of oral steroids can be used to treat nasal polyps initially. If there is response, this mode of management can be combined with a long-term course of intranasal steroid sprays ${ }^{9,10}$. Patients who do not respond may be referred for surgery.

Keywords: Nasal polyposis, methylprednisolone, rhinorrhea, nasal congestion, anosmia

NASAL polyposis is a condition resulting from chronic inflammation of the nasal and paranasal sinus mucosa, leading to a projection of benign edematous masses from the meatus to the nasal cavity. Multiple factors interact to initiate the surge of inflammatory responses that culminate in polypoid nasal growth ${ }^{1}$. Altered sinonasal functions lead to a variety of symptoms like nasal stuffiness and obstruction, anterior and posterior rhinorrhea, loss of the sense of smell, and facial pain. These make it the most incapacitating illness of the nasal cavity and paranasal sinuses ${ }^{2}$.

Corticosteroids are the mainstay in the medical management of nasal polyps. Systemic corticosteroids are considered the most effective pharmacological agents as they dramatically decrease mucosal inflammation and suppress the immune response against environmental 
ORIGINAL ARTICLES

Table 1. Dose of oral steroids as recommended by different authors

\begin{tabular}{|c|c|c|}
\hline Corticosteroid & Recommended dose & Author \\
\hline Dexamethasone & $12 \mathrm{mg}$ tapered to $3 \mathrm{mg}$ within 9 days & Lund, $1995^{13}$ \\
\hline \multirow[t]{2}{*}{ Methylprednisolone } & $64 \mathrm{mg}$ tapered to $10 \mathrm{mg}$ within 11 days & Rasp, $2000^{14}$ \\
\hline & $\begin{array}{l}1 \mathrm{mg} / \mathrm{kg} / \text { day tapered to } 1 / 4 \text { of the dose } \\
\text { within } 16 \text { days }\end{array}$ & Tuncer, $2003^{9}$ \\
\hline \multirow[t]{3}{*}{ Prednisolone } & $60 \mathrm{mg}$ tapered to $5 \mathrm{mg}$ within 16 days & van Camp, $1994^{6}$ \\
\hline & $1 \mathrm{mg} / \mathrm{kg} /$ day for 5 days & Bonfils, $2003^{10}$ \\
\hline & $1 \mathrm{mg} / \mathrm{kg} / \mathrm{day}$ for 10 days & Slavin, $1995^{16}$ \\
\hline Fluocortolone & $\begin{array}{l}560 \mathrm{mg} \text { oral tapered for } 12 \text { days or } 715 \\
\mathrm{mg} \text { tapered for } 20 \text { days }\end{array}$ & Damm, $1999^{5}$ \\
\hline
\end{tabular}

Table 2. Four-point grading scale for polyps (McKay and Lund)

\begin{tabular}{l|l} 
Grade 0 & $\begin{array}{l}\text { no polyps } \\
\text { small polyps not reaching the edge of the lower edge of } \\
\text { the middle turbinate } \\
\text { medium-sized polyps extending between the upper and } \\
\text { lower edges of the inferior turbinate }\end{array}$ \\
Grade III & $\begin{array}{l}\text { large polyps extending below the lower edge of the } \\
\text { inferior turbinate }\end{array}$
\end{tabular}

Table 3. Subjective Clinical Scoring System Symptom score: $0=$ absent; $1=$ mildest; $10=$ worst

\begin{tabular}{l|l|l|l}
1 & Headache & 8 & Cough \\
2 & Epistaxis & 9 & Post-nasal drip \\
3 & Rhinorrhea & 10 & Throat discomfort \\
4 & Congestion & 11 & Facial pain \\
5 & Sneezing & 12 & Eye complaints \\
6 & Itchiness & 13 & Fever \\
7 & Epiphora & 14 & Anosmia \\
\hline
\end{tabular}

Table 4. Score Scale System

\begin{tabular}{c|c} 
Grade & Score Scale \\
\hline 0 & 0 \\
I & $1-10$ \\
II & $11-20$ \\
III & $21-30$ \\
\hline
\end{tabular}

irritants and bacterial/fungal antigens ${ }^{3}$. They can reach all parts of the nose and sinuses, including the olfactory cleft and middle meatus, and can better improve the sense of smell, in contrast to intranasal topical steroids $s^{4}$

Woodworth ${ }^{3}$ demonstrated a significant decrease (radiographically and endoscopically) in extent of nasal polyps and an improvement of nasal symptom scores with systemic corticosteroids. Other studies of oral steroids reported success rates of 50 and $72 \% \%^{5,6}$, but these were non-randomized.

Most randomized control trials involving the use of topical intranasal steroids reported overall success rates between 60.9 to $80 \% \%^{7.8}$. Other studies combining a short-term course of oral steroids and a long-term course of intranasal steroids showed a reduction of polyp volume in 85 to $88 \%$ of patients with concomitant improvement in nasal symptoms ${ }^{9,10}$.

The main concerns with the use of systemic corticosteroids are adverse effects that can occur after prolonged use. Patients given daily doses of $100 \mathrm{mg}$ hydrocortisone (or the equivalent $20 \mathrm{mg}$ amount of synthetic steroid methylprednisolone) for longer than 2 weeks may undergo "latrogenic Cushing's Syndrome ${ }^{11 "}$. Other serious adverse effects include peptic ulcers and their consequences, hypomania or acute psychoses, sodium and fluid retention and loss of potassium ${ }^{11}$. In the management of nasal polyps, oral corticosteroids are given as a short-term course of 5-10 days with or without tapering ${ }^{12}$ or a longterm course of 12-21 days with tapering $3,3,6,9$ (Table 1).

This study aims to assess the efficacy of low-dose systemic corticosteroids given for 7 days in the treatment of nasal polyps.

\section{MATERIALS AND METHODS}

The study was conducted at the East Avenue Medical Center from August 2004 to September 2005. Of an initial 113 patients, 48 patients met the inclusion criteria: (1) age 18 years or older and (2) presence of nasal polyps on endoscopic examination. Excluded were patients with: (1) co-morbidities like diabetes mellitus, hypertension, acid peptic disease/gastritis, psychosis: (2) purulent sinonasal discharge; (3) use of rhinitis or asthma medications; (4) hypersensitivity to corticosteroids. Informed consent was obtained for the study.

The 48 patients were randomized equally into steroid and placebo groups using computer-generated numbers. The steroid group was treated with methylprednisolone, $16 \mathrm{mg}$ once a day after breakfast for 7 days. Clinical outcome measures included reduction of nasal polyps using the MacKay and Lund scoring system (Table 2) and improvement of symptom scores. Reduction of nasal polyps was defined as downgrade of polyp rating or decrease in size in those polyps that did not change in polyp grade.

Patients were seen at the clinic before, and a week after treatment and examined by the same physician. Nasal endoscopy was performed with a 30-degree Xenon sinuscope. Polyps were rated on the four-point grading scale proposed by MacKay and Lund ${ }^{15}$ (Table 2). Pre- and posttreatment video recordings were rated by 3 independent observers. 


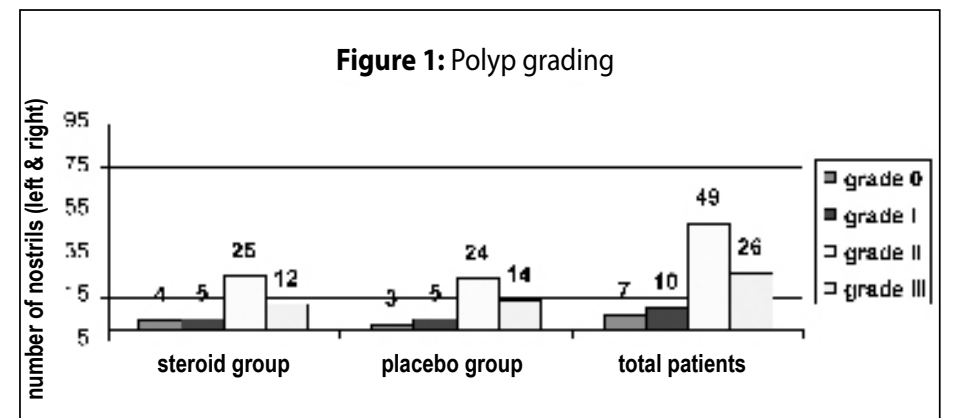

Figure 2-A: Reduction in polyp size in steroid group
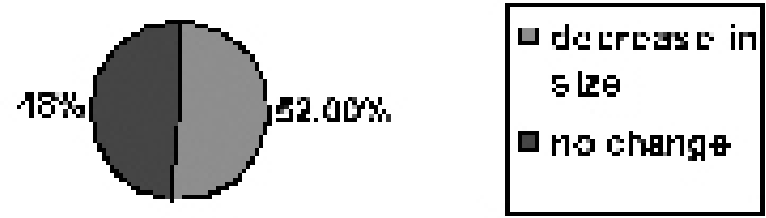

Figure 2-B: Reduction in polyp size in placedo group

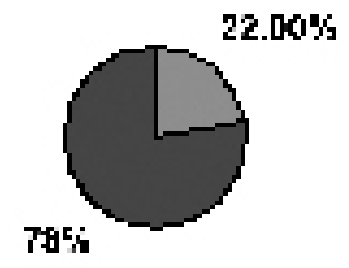

Table 5. Percentage of the different grades of polyps in total and in each group

\begin{tabular}{|c|c|c|c|}
\hline Grade 0 & $\begin{array}{c}\text { Total patients } \\
\text { (both nostrils) }\end{array}$ & $\begin{array}{c}\text { Medrol group } \\
\text { (both nostrils) }\end{array}$ & $\begin{array}{c}\text { Placebo group } \\
\text { (both nostrils) }\end{array}$ \\
Grade I & $7.61 \%$ & $8.70 \%$ & $6.52 \%$ \\
Grade II & $10.87 \%$ & $10.87 \%$ & $10.87 \%$ \\
Grade III & $53.26 \%$ & $54.35 \%$ & $52.17 \%$ \\
Total & $28.26 \%$ & $26.09 \%$ & $30.43 \%$ \\
\hline
\end{tabular}

Table 6. Size reduction of polyps

\begin{tabular}{|c|c|c|}
\hline & $\begin{array}{l}\text { Number of } \\
\text { patients in } \\
\text { steroid group }\end{array}$ & $\begin{array}{l}\text { Number of } \\
\text { patients in } \\
\text { placebo group }\end{array}$ \\
\hline $\begin{array}{l}\text { Downgrade of polyp in both nostrils by } \\
\qquad 1 \text { grade }\end{array}$ & $8(34.7 \%)$ & 0 \\
\hline $\begin{array}{l}\text { Downgrade of polyp in } 1 \text { nostril + } \\
\text { decrease in size but still in initial grade in } \\
\text { the other nostril }\end{array}$ & $2(8.70 \%)$ & 0 \\
\hline $\begin{array}{c}\text { Decrease in size but still in initial grade in } \\
\text { both nostrils }\end{array}$ & $2(8.70 \%)$ & $5(21.74 \%)$ \\
\hline No change & $11(47.83 \%)$ & $18(78.26 \%)$ \\
\hline $\begin{array}{l}\text { Total no. of patients with polyp reduction } \\
\text { (in all degrees) }\end{array}$ & $12(52.17 \%)$ & $5(21.74 \%)$ \\
\hline Total & $23(100 \%) t$ & $23(100 \%)$ \\
\hline
\end{tabular}

Table 7. Average change in polyp size

\begin{tabular}{|c|c|} 
Steroid group & Placebo group \\
-15.8696 & -2.6087 \\
\hline
\end{tabular}

$7 / 46(15.22 \%)$ had unilateral nasal polyps and 39/46 (84.78\%) had bilateral polyps. Polyps were graded per nostril since half of the patients (50\%) had different-sized polyps in each nasal cavity (Table 5). Grade 3 polyps were seen in $26 / 92$ (28.26\%) of the total number of nostrils examined during the initial consult. 49/92 (53.26\%) had grade 2 polyps and 10/92 (10.87\%) had grade 1 polyps. $7 / 92(7.61 \%)$ of the nostrils had grade 0 polyps (Figure 1).

In the steroid group, 8 out of the 23 patients had a one step grade reduction in both nostrils (Table 6). Another 2 patients had a one step grade reduction in 1 nostril while the polyp in the other nostril remained in the same grade but had a $20 \%$ decrease in size. Two (2) patients had a $30-50 \%$ decrease of nasal polyp size in both nostrils while remaining in the original grade. In all, 12 patients (52.17\%) had a reduction of nasal polyp size in various degrees after treatment with methylprednisolone. Using the Wilcoxon signed rank test, the reduction in nasal polyp size was statistically significant $(0.002$ and 0.004 in the right and left nostril respectively, at $\mathrm{P}<.05)$. There was an average $16 \%$ reduction in polyp size for patients who took methylprednisolone compared to the $3 \%$ 
reduction in those on placebo (Table 7).

In the placebo group, 5 patients out of the 23 (21.74\%) had a $10-50 \%$ reduction in nasal polyp size after treatment but still remained in the initial grade. This decrease was not statistically significant $(0.063$ and $0.066 \mathrm{in}$ the right and left nostril respectively, at $5 \%$ level of significance). Using the Mann-Whitney test, comparison of the size reduction between the 2 groups was statistically significant $(0.015$ and 0.034 in the right and left nostril respectively, at $5 \%$ level of significance).

Using the Wilcoxon signed rank test, the steroid group exhibited significant improvement in symptoms \# 1 to 7,9 to 11,13 and 14 (headache, epistaxis, rhinorrhea, congestion, sneezing, itchiness, epiphora, post-nasal drip, throat discomfort, facial pain, fever and anosmia, at $5 \%$ level of significance). There was a slight improvement in symptom \# 8 (cough, at 10\% level of significance) and \# 12 (eye complaints at $15 \%$ level of significance). In the placebo group, there was a significant improvement in symptoms \#1 to 5, 7 and 10 to 12 (headache, epistaxis, rhinorrhea, congestion, sneezing, epiphora, throat discomfort, facial pain and eye complaints, at $5 \%$ level of significance). There was a slight improvement in symptoms \# 6,9,13 and 14 (itchiness, post-nasal drip, fever and anosmia, at 10\% level of significance). Using the Mann-Whitney test, the steroid group was shown to have a significant improvement in symptoms \# 3, 4 and 14 (rhinorrhea, congestion and anosmia, at $6 \%$ level of significance) compared to the placebo group. There was also a slight improvement in treating symptoms \# 8 and 9 with methylprednisolone than with placebo (cough and post-nasal drip, at $17 \%$ level of significance). There was no significant difference in improvement in the other symptoms between the 2 groups, nor were there adverse effects reported in either group.

\section{DISCUSSION}

The characteristics of the study population reflect those of patients with nasal polyps in the general population ${ }^{16}$ with reference to age (mean age, 35.30 years) and male-to-female ratio (2:1).

The results of the study showed that there was a significant decrease in polyp size among patients in the steroid group by 1 grade. The volume of the polyps was reduced in $12 / 23$ patients $(52.17 \%)$ by an average of $16 \%$. Among these 12 patients, 10 reported general improvement in a majority of their symptoms based on the subjective clinical scoring system. There was also a significant difference when comparing the reduction in nasal polyps to that in the placebo group. These findings correspond to those of Damm et al. ${ }^{9}$ where oral steroid therapy (oral fluocortolone $560 \mathrm{mg}$ tapered for 12 days in group 1 and $715 \mathrm{mg}$ tapered for 20 days in group 2) significantly reduced the extent of polyps on magnetic resonance imaging (>30\%) in $50 \%$ of patients and diminished most sinus-related symptoms in $80 \%$ of the patients.

The symptom scores of the patients in both steroid and placebo groups improved for most symptoms. However, the steroid group had significantly better improvement in the symptoms of rhinorrhea, congestion and anosmia compared to placebo.

This study showed that a low dose, short-term treatment course of oral methylprednisolone ( $16 \mathrm{mg}$ a day for 7 days) can lead to significant reduction in the size of nasal polyps, and improvement of nasal symptoms of rhinorrhea, congestion and anosmia. This treatment course can also be used as a screening tool prior to prescribing intranasal steroid sprays, which are quite expensive. Non-responders can be referred for surgery, avoiding further costly medical management.

\section{ACKNOWLEDGEMENTS:}

We would like to thank Dr. Felix Nolasco for facilitating this study; Drs. Dwight Alejo, Martin Derek Peteza, Ramon Portugal III, Emerson Catudio, Ryan Adan, Nino Timbungco and Stephanie Santiago, our participating investigators; and Ms. Menchie Gapasin, our statistician.

\section{REFERENCES}

1. Shin SH, Park JY, Jeon CH, Choi JK, Lee SH. Quantitative Analysis of Eotaxin and RANTES Messenger RNA in Nasal Polyps: Association of Tissue and Nasal Eosinophils. Laryngoscope 2000;110(8):1353 7.

2. Radenne F, Lamblin C, Vandezande LM, et al. Quality of Life in Nasal Polyposis. J Allergy Clin Immunol 1999;104:79-84

3. Woodworth B, Joseph K, Kaplan A, Schlosser, R. Alterations in Eotaxin, Monocyte Chemoattractant Protein-4, Interleukin-5, and Interleukin-13 After Systemic Steroid Treatment for Nasal Polyps. Otolaryngol Head Neck Surg 2004;131(5):585-9.

4. Assanasen P, Naclerio R. Medical and Surgical Management of Nasal Polyps. Current Opinion in Otolaryngology \& Head \& Neck Surgery 2001;9(1):27-36.

5. Damm M, Jungelhulsing M, Eckel H, Schmidt M, Theissen P. Effects of Systemic Steroid Treatment in Chronic Polypoid Rhinosinusitis Evaluated with Magnetic Resonance Imaging. Otolaryngol Head Neck Surg 1999;126:517-23

6. van Camp C, Clement PA. Results of Oral Steroid Treatment in Nasal Polyposis. Rhinology 1994 Mar;32(1):5-9.

7. Tos,m, Svendstrup F, Arndal H, Orntoft S, et al. Efficacy of an Aqueous and a Powder Formulation of Nasal Budesonide Compared in Patients with Nasal Polyps. Am J Rhinol 1998;12:183-9.

8. Lildholdt T, Rundcrantz H, Lindqvist N. Efficacy of Topical Corticosteroid Powder for Nasal Polyps: A Double-Blind, Placebo-Controlled Study of Budesonide. Clin Otolaryngol 1995;20:26-30.

9. Tuncer U, Soylu L, Aydogan B, Karakus F, Akcali C. The Effectiveness of Steroid Treatment in Nasal Polyposis. Auris Nasus Larynx 2003;30:263-8.

10. Bonfils $\mathrm{P}$, Nores JM, Halimi $\mathrm{P}$, Avan P. Corticosteroid Treatment in Nasal Polyposis with a Three-Year Follow-Up Period. Laryngoscope 2003;113:683-687.

11. Chrousos G, Margioris A. Adrenocorticosteroids \& Adrenocortical Antagonists. In: Katzung B, ed Basic \& Clinical Pharmacology 8th edition. New York: The McGraw-Hill Companies, Inc., 2001:66078

12. Medical Management of Nasal Polyps in Adults. In: UP-PGH Department of Otorhinolaryngology Clinical Practice Guidelines. 2003:8-13.

13. Lund V. Diagnosis and Treatment of Nasal Polyps. BMJ 1995;311:1411-14.

14. Rasp G, Kramer MF, Ostertag P, Kastenbauer E. A New System for the Classification of Ethmoid Polyposis. Effect of Combined Local and Systemic Steroid Therapy. Larynorhinootologie 2000 May;79(5):266-72.

15. MacKay IS, Lund VJ. Imaging and staging. In: Mygind N, Lilholdt T, eds. Nasal Polyposis: An Inflammatory Disease and Its Treatment. Copenhagen: Munksgaard, 1997:137-144.

16. Slavin R. Nasal Polyps and Sinusitis. JAMA 1997;278(22):1849-54. 